\begin{tabular}{|l|l|l||}
\hline \multicolumn{2}{|c|}{ PublisherInfo } \\
\hline \hline PublisherName & $:$ & BioMed Central \\
\hline \hline PublisherLocation & $:$ & London \\
\hline \hline PublisherImprintName & $:$ & BioMed Central \\
\hline \hline
\end{tabular}

\title{
Back to normal after ICU?
}

\begin{tabular}{|l|l|l||}
\hline \multicolumn{2}{|c||}{ ArticleInfo } \\
\hline \hline ArticleID & $:$ & 4093 \\
\hline \hline ArticleDOI & $:$ & $10.1186 /$ ccf-1999-1424 \\
\hline \hline ArticleCitationID & $:$ & 1424 \\
\hline \hline ArticleSequenceNumber & $:$ & 30 \\
\hline \hline ArticleCategory & $:$ & Paper Report \\
\hline \hline ArticleFirstPage & $:$ & 1 \\
\hline \hline ArticleLastPage & $:$ & 4 \\
\hline \hline & & RegistrationDate : 1999-8-19 \\
\hline ArticleHistory & $:$ & OnlineDate \\
\hline \hline ArticleCopyright & $:$ & Current Science Ltd1999-8-19 \\
\hline \hline ArticleGrants & $:$ & \\
\hline \hline ArticleContext & $:$ & 130541111 \\
\hline \hline
\end{tabular}




\section{Keywords}

quality of life, intensive care unit, critical care, cost accounting, outcome assessment, activities of daily livin, health status, length of stay, Nottingham Health Profile, cost benefit analysis

\section{Comments}

This interesting study examines the long-term effects on quality of life for patients who are admitted to ICU for a prolonged period of time. This aspect of ICU care is rarely studied but is important in terms of health economics. The use of understandable health evaluation indices makes the data comprehensible. It also has importance for rehabilitation efforts and expenditure to improve the life of ICU survivors.

\section{Introduction}

Approximately half of all intensive care unit (ICU) resources (ICU) are consumed by the $10 \%$ of ICU patients who require prolonged admission to the ICU. Few studies have examined the outcome in this group of patients. The authors decided that an appropriate assessment of the efficacy of care would be the comparison of this group with the general population using a standardized and validated quality-oflife instrument (Nottingham Health Profile and a modified Activities of Daily Living index).

\section{Aims}

To assess the subjective health status, quality of life and functional ability of patients whose intensive care stay was prolonged. These factors were compared with those of the general population.

\section{Methods}


Following approval by the hospital's Institutional Review Board, the subjects studied were a consecutive sample of 718 patients who were admitted to a tertiary care center's ICU over a 45 month period. Eligible patients were over 18 years of age and had an ICU stay of greater than $96 \mathrm{~h}$. Collected data on these patients included age, gender, diagnosis and APACHE II score. The patients' records were also checked retrospectively for baseline health status.

Six months after ICU admission the survivors were sent a questionnaire that evaluated their quality of life using the Nottingham Health Profile and a modified Activities of Daily Living index.

\section{Results}

The ICU admitted 6531 patients during the study period; 718 adult patients $(11.3 \%)$ had a prolonged ICU stay. This group had ICU and hospital mortality rates of $17.7 \%$ and $26.7 \%$ respectively. There were 470 survivors at six months, of whom 368 (78.3\%) returned the questionnaire.

Compared to the general population, the subjective health status was best among patients who were admitted to ICU following open-heart surgery. Patients admitted following trauma or respiratory failure deteriorated in all aspects studied, including pain, sleep, social isolation and emotional reactions.An increasing length of ICU stay was related to a high degree of handicap in physical mobility. Most patients $(85 \%)$ were independent for their Activities of Daily Living. The cost of each survivor was calculated to be US $\$ 36,579$.

\section{Discussion}

This study found that, although the subjective health status and performance of Activities of Daily Living were largely intact, the survivors were not comparable to the general population. The psychosocial aspects of quality of life were restored more rapidly than physical performance. Quality of life that most closely approached the quality for the general population was found in the groups of patients who had undergone open heart surgery or who were over 65 years old; however, all patients at six months after ICU stay had physical problems with mobility. In the study, $32.8 \%$ of patients less than 63 years old had retired and half had a history of chronic disease. The authors tried to account for the difference in population chronic health scores. The authors also feel that the ICU and general population may differ in socio-economic background, which is an important factor affecting quality of life. In previous studies, well-being in sleep, pain, and physical mobility was associated with a higher educational status, and unemployed women experienced more distress in all quality-of-life dimensions.

The quality of life after ICU admission appears to be most influenced by problems in physical mobility. Younger patients seem to suffer more from physical and psychosocial impairments. Openheart-surgery patients had the most positive improvement in assessment of health status. 
The authors accept that their follow-up at only six months may be responsible for the predominance of problems in physical function. They suggest that further improvement may occur later. The deterioration in the quality of life of ICU patients correlated with admission diagnosis and tended to decrease with increasing age. Certain patients (trauma and respiratory failure) were found to have a prolonged convalescence and further efforts should be made for their rehabilitation.

\section{References}

1. Niskanen M, Ruokonen E, Takala J, Rissanen P, Kari A: Quality of life after prolonged intensive care. Crit Care Med. 1999, 27: 1132-1139

This PDF file was created after publication. 